\title{
Gastroepiploic Artery
}

National Cancer Institute

\section{Source}

National Cancer Institute. Gastroepiploic Artery. NCI Thesaurus. Code C52857.

One of two (right and left) arteries along the greater curvature of the stomach that supply blood to the greater omentum and stomach. 